\title{
Etkili Illetişimin Hasta Güvenliği Kültürü Üzerine Etkisi ve İç Girişimciliğin Aracı Rolü: Bir Özel Hastane Uygulaması
}

\author{
ALI ARSLANOĞLU* \\ aliarslanoglu18@gmail.com \\ ORCID ID: 0000-0002-4454-0397
}

Öz: Hasta güvenliği önemini artan bir konudur. Hasta güvenliği için hasta güvenliği kültürünü artırmak gereklidir. Bu çalışmadaki amaç hasta güvenliği kültürünü artırmak için etkili iletişimin etkisini ve iç girişimciliğin aracı rolünü belirlemeye çalışmaktır. Araştırmada daha önce geçerlilik ve güvenirliliği yapılmış olan etkili iletişim, iç girişimcilik ve hasta güvenliği kültürü̈ ölçekleri kullanılmıştır. İstanbul ilinde faaliyet gösteren bir özel hastane çalışanları araştırmanın evrenini oluşturmaktadır. Araştırmaya 498 kişi katılmıştır. Araştırma Eylül 2018-Aralık 2018 tarihleri arasında yapılmıştır. Araştırmaya katılanların; \%75,5'i kadın, \%54,8'i evli, \%87,3'ü 40 yaş altında, \%29,9’u ön lisans, \%29,5'i lisans mezunu, \%50,4'si haftalık 41-50 saat arasında çalı̧̧an ve \%48,8'inin hemşire olduğu görülmektedir. Araştırma değişkenlerinin ilişkisi 0,196, 0,402 ve 0,452 olarak bulunmuştur. Etkili iletişim ve iç girişimciliğin, hasta güvenliği kültürünü etkilediği hipotezleri desteklenmişsir. Etkili iletişsimin iç girişimciliği etkilediği hipotezi desteklenmiştir. Etkili iletişimin hasta güvenliği kültürü üzerine etkisinde iç girişimciliğin aracı etkisi olduğuna dair hipotez desteklenmemiştir.

Anahtar kelimeler: Etkili iletişim, İç girişimcilik, Hasta güvenliği kültürü.

\section{Giriş}

Kalite her alanda olduğu gibi sağlık hizmetleri alanında çok önemli bir yer tutmaktadır. Sağlık hizmetlerinde kalite amaçlarından birisi hasta güvenliğidir. Hasta güvenliğini artırmanın önemli faktörlerinden birisi de hasta güvenliği kültürüdür.

İletişim her alanda etkili bir parametredir. İletişim sayesinde tüm bilgiler sağlıklı bir şekilde kişiden kişiye, kurumdan kuruma yayılmaktadır. İletişim; anlamak, anlatmak ve anlaşılmak için önemli bir enstrümandır. Bu enstrümanı etkili kullananlar birçok sorunun önüne geçebilirler.

İnovasyon ve yenilikçilik kurumlar için önemli bir faaliyettir. Yenilikçilik için insanların girişimcilik faaliyetlerinde bulunması önemlidir. Sadece dış girişimcilik değil

\footnotetext{
* Dr. Öğr. Üyesi, Sağlık Bilimleri Üniversitesi, Sağlık Bilimleri Fakültesi.
} 
aynı zamanda iç girişimcilik kurum içinde önemlidir. İç girişimci özelliğine sahip çalışanlar kurum içinde süreç, ürün ve hizmet konusunda yenilikler yapmak için sürekli çalışmaktadırlar.

Araştırmanın amacı, etkili iletişim hasta güvenliği kültürü ve iç girişimcilik arasındaki ilişkiyi belirlemektir. Aynı zamanda etkili iletişimin hasta güvenliği kültürü üzerine etkisi ve iç girişimciliğin aracı etkisini belirlemektir. Çalışmanın sağlık sektörüne katkı sağlayacağı düşünülmektedir.

\section{Kavramsal Çerçeve}

\section{Etkili İletişim}

İletişim, yönetim sürecinin önemli bir parçasıdır. Çünkü etkili iletişim olmaksızın ne bireyler yapacakları işlerden haberdar olabilir ne de soruların yanıtlanması, problemlerin çözülmesi, geribildirim sağlanması ya da sonuçların değerlendirilmesi mümkün olabilir. ${ }^{1}$ İletişimi kısaca. "Bilgi üretme, aktarma ve adlandırma süreci" olarak tanımlayabiliriz. Genel anlamda, iletişimin gerçekleşmesi için iki sistem gereklidir. Bu sistemler iki insan, iki hayvan, iki makine olabilir, seçenekleri artırmak mümkündür. Nitelikleri ne olursa olsun, iki sistem arasındaki bilgi alışverişini “iletişim”" kabul edebiliriz. ${ }^{2}$ İletişim bir süreçtir. İster kişiler arası olsun ister kişi ve bir başka topluluk arasında olsun, temelde iletişim süreci aynıdır değişmez. ${ }^{3}$ İletişim, Latince, "communis" kelimesinden kaynaklanmıştır. En geniş anlamıyla iletişim, bilginin bir kişiden diğerine iletilmesidir. ${ }^{4}$ Sonuç olarak iletişim, "Her iki taraftaki bilgileri eşitlemek için gönderici ile alıcı arasında bilgi alışverişi süreci”dir. ${ }^{5}$ İletişim, oldukça kompleks, dinamik ve gelişen bir yetenektir. ${ }^{6}$ Bazı araştırmacılar görüşlerin, fikirlerin ve amaçların alışverişini içerdiğinden iletişimi dinamik doğası nedeniyle bir süreç olarak tanımlamışlardır. ${ }^{7}$ İletişim bir örgüt vasıtasıyla bir işletmeden diğerine bilgi transferi yani bilgi yayan araçtır. ${ }^{8}$

Şirketler müşterileri ile etkileşimlerini geliştirmek ya da organizasyon performanslarını artırmak niyetindeler ise geleneksel pazarlama yaklaşımları yeterli değildir.9 Şirket ya da organizasyon içinde etkin iletişim, içsel pazarlama ve müşte-

1 Richard M. Hodgetts, Yönetim, Teori, Süreçve Uygulama, çev., Canan Çetin ve Esin Can Mutlu, İstanbul: Beta basım yayım Dağıtım A.Ş., 1999, s.445.

2 Üstün Dökmen, İletişim Çatışmaları ve Empati, İstanbul: Sistem Yayıncılık, 2003, s.19.

3 Şaban Kızıldağ, İletişimde Mazeret Yok, İstanbul: Hayat Yayınları, 2014, s.34.

4 Joann Keyton ve Pamela Shockley Zalabak, Case Studies for Organizational Communication: Understanding Communication Processes, Los Angeles: Roxbury Publishing Company. 2006, s.421.

5 Nima Norouzi vd., "The Architect, The Client and Effective Communication İn Architectural Design Practice", Procedia-Social and Behavioral Sciences, 172/1 (2015), s.635.

6 Tiago R. Matos, “The Challenge of Effective Communication Among Scientists”, Journol Of Investigative Dermatology, 137/11 (2017), s. 183.

7 Ayodele Elijah Olusegun, A.V.O., "Communications in The Building Industry of Nigeria- İmplications For Clients", (2008), s.51.

8 Ian N. Lings ve Gordon E. Greenley, “Measuring Internal Market Orientation”, Journal of Service Research, 7/1 (2005), s.290.

9 Wann-Yih Wu, Chia-Chun Tsai ve Chen-Su Fu, “The Relationships Among Internal Marketing, Job Satisfaction, Relationship Marketing, Customer Orientation, and Organizational Performance: An Empirical Study of TFTLCD Companies in Taiwan”, Human Factors and Ergonomics In Manufacturing \&Service Industries, 23/5 (2013), 
ri odaklılığının geliştirilmesi için gerekmektedir. İç iletişim, çalışanların müşterilere hizmet ederken gerekli bilgileri alması ve şirketin politikalarını ve stratejilerini bilmesine yardımcı olabilir. ${ }^{10}$ Yöneticiler ve çalışanlar arasında iki yönlü iletişim, çalışanlara sadece yönetimin desteğini artırması değil aynı zamanda kendi iş performansını artırmak için geribildirim sağlar. ${ }^{11}$ Bir işin başarılı ya da başarısız olması, işin tekniğini bilmekten çok, iletişim kurabilme becerisine bağlıdır. ${ }^{12}$

\section{Hasta Güvenliği Kültürü}

Tibbi hatalar ile yaralanma ve ölümler sağlık sistemi üzerine güven kaybı ve anlamlı bir şekilde ekonomik maliyetlerde artış ile büyük bir kamu sağlık problemlerine neden olmaktadır. ${ }^{13}$ Bakım kalitesi Institute of Medicine (IOM) tarafından, bireylerin ve toplumların sağlığının derecesini mevcut mesleki bilgilerle sürdürmek ve istenilen sağlık çıktılarına ulaşma olasılığını artırmak olarak tanımlamıştır. ${ }^{14}$ IOM sağlık hizmetlerinde kalite için 6 amaç önermektedir. Bunlar, hasta güvenliği, hasta merkezlilik, etkililik, verimlilik, zamanlama ve eşitliktir. ${ }^{15}$

Hasta güvenliği ve yüksek kalitede bakım, tüm sağlık hizmetleri uygulamalarının temel unsurlarıdır. ${ }^{16}$ Hasta güvenliği kültürünün değerlendirilmesi, hastalar için tıbbi hizmetlerin kalitesini arttırmak için kritik bir yaklaşım olarak kabul edilmiştir. ${ }^{17}$ Hasta güvenliği kültürü; hasta güvenliği ve sağlık hizmetlerinde kaliteyi etkileyen önemli faktörlerinden biri olarak tanımlanmıştır. ${ }^{18}$

Birçok araştırma, sağlık ekibi üyeleri arasındaki zayıf iletişim ve iş birliğinin daha yüksek tıbbi hata riskine yol açabileceğini bildirmiştir. ${ }^{19}$

\section{İç Giriş̧imcilik}

Girişimcilik, girişimci ve izleyicilerin değerine yeni bir şeyler yaratmak ve yaratılış sürecini içerir. ${ }^{20}$ Girişimci sözcüğü hem günlük yaşamda hem de yönetim ve ekonomide bir teknik terim olarak sıklıkla kullanılır; girişimci, aslında "belirli proje tek-

\footnotetext{
s.436.

10 Christian Gronroos, Service Management and Marketing, Massachusetts: Lexington Boks, 1990. s.27

$11 \mathrm{Wu}$, Tsai ve Fu, “The Relationships Among”, s.437.

12 Jo Condrill ve Bennie Bough, 101 İletişim Yolu, çev. Aslı Şahin, İstanbul: Beyaz Yayınları, 2000, s.1.

13 Joanna K. Weinberg, "Medical Error and Patient Safety: Understanding Cultures in Conflict", Law\& Policy, 24/2 (2002), s.93.

14 Robert M. Wachter, Understanding Patient Safety, Columbus, Ohio: The McGraw-Hill Companies, 2008, s.20. 15 Nilay Gemlik, Hastane Yönetiminde 4 Boyut, Ankara: Nobel Akademik Yayıncılık, 2018, s.45.

16 Manfred Mortell, "Is there a Theory - Practice - Ethics Gap? A Patient Safety Case Study", International Journal of Africa Nursing Sciences, 10/1 (2019), s.38.

17 Chih-Hsuan Huang, Hsin-Hung Wu ve Yi-Ching Lee, “The Perceptions of Patient Safety Culture: A Difference Between Physicians and Nurses in Taiwan”, Applied Nursing Research, 40/3 (2018), s.40.

18 Institute of Medicine, Keeping Patient Safe: Transforming The Environment Of Nurses, Washington DC: National Academy Press, (2004), s.13.

19 "Advancing Effective Communication, Cultural Competence, and Patient- and Family-Centered Care: A Roadmap For Hospitals", The Joint Commission, erişim 18 Mart, 2019, http://www.jointcommission.org/ assets/1/6/ ARoadmapforHospitalsfinalversion727.pdf.

20 Zülfikar Ali Bokhari, "Supportıng Entrepreneurshıp and Intrapreneurshıp at Unıversitıes for Small Busıness Development from Marketıng Perspectıve Is The Key to Support Community, Faculty and Students", Contracts With Large Multinational Corporations: A Hurdle, MMA Fall Educators' Conference, 2006, s.94.
} 
liflerini üstlenerek, girişimciliğin doğasını anlayan ve gelişime açan insan demektir”. $\mathrm{Bu}$ açıdan girişimcilik girişimcinin yaptığ 1 iştir. ${ }^{21}$

Bir başka tanıma göre girişimcilik, yeni ya da mevcut bir organizasyon içinde, yaratıcılık ve yenilik yapma yoluyla değer yaratma amacıyla bir fırsatın ortaya çıkarılması ve geliştirilmesi, bu fırsatlardan yararlanma süreci olarak tanımlanmaktadır. Bu tanımda girişimcilik hem bireysel hem de işletme bazında ele alınmıştır. ${ }^{22}$

İç girişimcilik kavramı çeşitli biçimlerde ele alınmaktadır. Genel olarak iç girişimcilik (intrapreneurship), örgüt içinde çalışmakta olan bireylerin işyerlerinde ürün, hizmet ve süreç inovasyonu ile sonuçlanan faaliyetlerde bulunması olarak tanımlanmaktadır. ${ }^{23}$ The American Heritage Dictionary of the English Language, iç girişimciyi (intrapreneur) "büyük bir firma içinde bir fikri, risk alma ve yenilik yapma yoluyla karlı nihai bir ürüne dönüştürme sorumluluğunu üstlenen kişi” olarak tanımlamaktadır. ${ }^{24}$

Yapılan bir çalışmada, şirketler tarafından belirlenmiş olan girişimciliğinin gelişmesi için elverişli bir ortam olarak temel dört faktör tanımlanmıştır. Bunlar; teknik yeteneklere sahip iş gücü, organizasyonun düzeni, pazar bilgisi ve gizliliğin mevcudiyetidir. ${ }^{25}$ Literatürde iç girişimciliğin boyutları şu şekilde sıralanmıştı: ${ }^{26}$ (I)Yenilik yapma (İnovasyon), (II)Risk alma, (III) Öngörücü olma (Proaktiflik), (IV) Özerklik (Otonomi), (V) Yeni iş girişimleri başlatma, (VI) Kendini yenileme veya stratejik yenilenme, (VII) Rekabetçi girişkenlik.

\section{İletişim, İç Girişimcilik ve Hasta Güvenliği Arasındaki İlişski}

Hasta güvenliği olaylarını azaltmak için, iletişim sistemlerini iyileştirme çabaları hasta güvenliğini sağlamak için önemli stratejiler olarak vurgulanmıştır. ${ }^{27,28}$ Bununla birlikte, basitçe bir iletişim stratejisi sağlamak, diğer kritik faktörler dikkate alınmadığı takdirde hiçbir şekilde fark yaratmayacaktır. ${ }^{29}$

İletişim hasta bakım sürecinin önemli bir bileşeni olması sebebiyle önemlidir. Sağlık çalışanları arasındaki iletişim ise bu süreci doğrudan etkileyen, bazen de kendisi etkilenebilen bir biçimde hasta bakım sürecini tamamlayan diğer önemli unsur

21 Sudi Apak, Kamer H. Taşçıyan ve Muzaffer Aksoy, Girişimcilik ve Sermaye Tedarik Yöntemleri, İstanbul: Papatya Yayıncilık, 2010, s.41.

22 Ahmet Şahbaz ve Ümran Şahbaz, “İnovasyon ve Girişimcilik”, Uluslararası Girişimcilik ve Kariyer Sempozyumu,1-3 Kasım, 2013, s.119.

23 Nurettin İbrahimoğlu ve Özlem Yaşar Uğurlu, “KOBİ’erde İç Girişimcilik ve Örgüt Kültürü İlişkisi: Sektörel Bir Araştırma”, H.Ü. İktisadi ve İdari Bilimler Fakültesi Dergisi, 31/1, (2013), s. 105.

24 Veysel Ağca ve Mustafa Kurt, “İç Girişimcilik ve Temel Belirleyicileri: Kavramsal Bir Çerçeve”, Erciyes Üniversitesi İktisadi ve İdari Bilimler Fakültesi Dergisi, 0/29 (2007), s.85.

25 Nimalathasan Balasundaram ve Mohammad Shabab Uddin, "Determinants of Key Favorable Environment for Intrapreneurship Development: an Empirical Study of Some Selected Companies in Chittagong, Bangladesh", BULETINUL Universităţii Petrol - Gaze din Ploiești, LXI/2 (2009), s.34.

26 Bostjan Antoncic ve Robert D. Hisrich, "Clarifying The Intrapreneurship Concept" Journal of Small Business and Enterprise, 10/1 (2003), s.15.

27 Jennifer Tjia vd., "Nurse-Physician Communication in The Long-Term Care Setting: Perceived Barriers and Impact On Patient Safety", Journal of Patient Safety, 5/3 (2009), s.146.

28 "National patient safety goals: Long term care program", The Joint Commission, erişim 18 Mart, 2019, http:// www.jointcommission.org/assets/1/6/NPSG_Chapter_Jan2012_LTC.pdf.

29 Margo Paterson vd., “The Timely Open Communication for Patient Safety Project”, Journal of Research in Interprofessional Practice and Education, 3/1, (2013), s.24 
olarak karşımıza çıkmaktadır. ${ }^{30}$

Hasta güvenliğinde iletişimin kapsamı; ${ }^{31}$

1. İletişim, hasta için en iyi bakımı sürecini garanti etmek, hasta ve ilgili diğer profesyoneller ile bakım amaç ve hedeflerini paylaşmak için temel araçtır.

2. Tıpta iletişim genellikle stres ve zaman baskısı altında gerçekleşir.

3. İletişim özellikle zor durumlarla başa çıkmak için bize yardımcı olabilir. İletişim belirsizliklerde uzmanlaşmak ve hasta güvenliği için tehlikeleri önlemek için, takım içinde ve meslektaşları ile iş birliğini geliştirebilir.

Öncelikle kültür değişimini gerçekleştirmek gerekir. İletişim kanallarını açmak, her düzeyde, özellikle de hata konularında sistem güvenliği analizlerini uygulamak gerekir.

Kuvvetli bir iletişim planı için: ${ }^{32}$

- Gözle görülür bir lider desteği

- İyileşmeyi değerlendirmede kullanılacak “metriklerin” çok iyi belirlenmesi, uygulama öncesi ve sonrası değerlendirilmelerde kullanılması,

- Kısa dönem başarılarının duyurulması, kutlanması ve tüm çalışanlar tarafından paylaşılmasının sağlanması,

- Uzun süreli başarılar için takım çalışmaları ve takım olarak çalışmanın iyileştirilmesi programlarının uygulanması,

- Hasta ve ailesi ile ortaklık kurulması gerekmektedir.

İletişim sürecinin hasta güvenliği açısından üstlendiği rolün davranışsal boyutunun yanı sıra teknik boyutu ile de tartışılması ve "nasıl” in bilgisinin paylaşılması gerekmektedir. Bu kapsamda hasta güvenliğine ilişkin yazılı, görsel ve işitsel materyallerin kullanımı önerilebilir. Afiş, poster, bülten, klinik panoları görsel eğitimin de bir parçası olarak hasta güvenliğinin, ulaşılmak istenen hedeflerin ve hasta güvenliğinin o hastanede hangi politikalar, prosedürler, talimatlar doğrultusunda günlük çalışmayı düzenlediğinin duyurulması açısından önem taşımaktadır. Özellikle klinik panoları hasta güvenliğine ilişkin olarak takip edilen indikatörler bazında yapılan ölçüm sonuçlarının ve iyi uygulama örneklerinin paylaşımına imkân veren çok işlevsel iletişim araçları olarak kullanılabilir. ${ }^{33}$

30 T.C. Sağlık Bakanlığı, SKS Işı̆̆ında Sağlıkta Kalite Kitabı, Cilt 2, Ankara: Sağlık Hizmetleri Genel Müdürlüğü, 2012, s.141. Joel Medrano-Mariscala, "Reflections on The Concept of Communication: Second International Goal of Patient Safety", Rev Med Inst Mex Seguro Soc., 53/4 (2015), s.520. Susan B. Childress, “Team Communication: It's About Patient Safety", Journal of Oncology Practice, 11/1, (2015), s.23.

31 Martin Beyer vd., Communication and Patient Safety, Massachusetts: Blackwell Publishing Ltd., 2007, s.16.

32 Şükran Yalçın ve Adile Acar, "Avrupa Birliği Ülkelerinde Hasta Güvenliği ve Güvenli Hastane İlişkisi”, II. Uluslararası Sağlıkta Performans ve Kalite Kongresi Kitabı, 1/1 (2010), s. 22.

33 Bilçin Tak, "Sağlık Hizmetlerinde Kalitenin Ana Unsuru Olarak Hasta Güvenliği Sistemlerinin Oluşturulması: Hastaneler İçin Bir Yol Haritası Önerisi”, Sağlıkta Performans ve Kalite Dergisi, 1/1 (2010), s.98-99. 
Etkili iletişim, hasta güvenliği için çok önemlidir. Kök neden analizleri ile ilgili bir çalışma önermektedir ki hataların \%60’ından fazlasında, zayıf iletişim önemli bir nedensel faktör olduğunu göstermektedir. Etkili iletişim, aynı zamanda ortaya çıktıktan sonra bir olayı yönetmek için çok önemlidir. ${ }^{34}$

Çalışmalar iletişim sorunlarının tıbbi hataların ana kaynağı olduğunu göstermiştir. Güvenli bakım; farklı eğitim, öğretim ve deneyimi ile farklı görevleri yerine getiren bireyler arasındaki iletişimi gerektirir. ${ }^{35}$

JCI tarafından 2006 yılında yapılan bir çalışmaya göre; iletişim hataları rapor edilmiş sentinel olayların en büyük kaynağıdır ve yine zayıf iletişimin klinik uygulamalarda ki önlenebilir zıt olaylara yol açan temel faktörlerden biri olabileceğini göstermiştir. ${ }^{36}$

Sağlık iletişimi rehberlik ve denetleme programları, eğitim oturumları ve toplantılar aracılığıyla yönetim tarafından başlatılabilir. İletişim aynı zamanda klinik bilgilerin zamanında paylaşımı destekleyen, güvenli ve yüksek kaliteli bakım sağlayan doğaçlama bir süreç olduğunu göstermiştir. ${ }^{37}$

Hasta güvenliğini arttırmak için zamanında açık iletişim kurmanın; iletişim, iş birliği, liderlik, mesleki gelişim, çalışma ortamı ve takım gururu gibi birbirine bağlı bileşenlerden oluşan karmaşık bir süreç olduğunu göstermektedir. ${ }^{38}$

İletişim tıp uygulamalarının önemli bir parçasıdır. Aynı zamanda, hastanın güvenliği için çok önemlidir. Sağlı sektöründe iletişimin öğrenilmesinin farkındalığı giderek artmaktadır. ${ }^{39}$ Hastalar ve çalışanlar arasındaki etkili iletişim, güvenli hasta bakımının özelliklerinden birisidir. ${ }^{40}$

Bir kurum ve kuruluşun etkili, etkin ve verimli olmasında en önemli kaynaklarından birisi de insan kaynağıdır. Son yıllarda bu kaynağın farkına varan kurum ve kuruluşlar çalışanları için içsel pazarlama uygulamalarını yapmaya başlamışlardır. İçsel pazarlama uygulamaları, yani ödül ve motivasyon, etkili iletişim, iş gören gelişimi, çalışan seçimi, personel alımı, destek sistemi, güçlendirme gibi uygulamalar yerinde ve zamanında uygulanırsa çalışanların iş tatmini, örgütsel bağlılığı, performansı, memnuniyeti ve müşteri yönlülüğü arttığı görülmüştür. Liderler iç girişimci olan çalışanlarına daima destek vermelidirler. ${ }^{41}$

34 WHO, Patient Safety, Learning From Error, Fransa.WHO Library Cataloguing-in-Publication Data, 2010, s.12. 35 Carmen Daniela Domnarıu, "Patient Safety Culture at Organizational Level", Public Health and Management, Acta Medica Transilvanica, 2/3 (2012), s.146.

36 Ying Hua vd., "Effects of Nursing Unit Spatial Layout on Nursing Team Communication Patterns, Quality of Care, and Patient Safety", HERD, 6/1, (2012), s.9.

37 Hua vd., "Effects of Nursing", s.9.

38 Paterson vd., “The Timely Open” s.24.

39 Ann Faulkner, Jackie Argent ve Avril Jones, "Effective Communication in Health Care: Exploring The Skills Of The Teachers", Patient Education and Counseling, 45/3 (2001), s.227.

40 Audrey Lyndon, Marya G. Zlantik ve Robert M. Wachter, "Effective Physician-Nurse Communication: A Patient Safety Essential For Labor And Delivery”, American Journal of Obstetrics-Gynecology, 205/2 (2011), s.91. 41 Güven Bektemür, "İç Girişimciliğin Hasta Güvenliği Kültürü Üzerine Etkisi: Bir Özel Hastane Uygulaması", Să̆ Aka Derg, 5/3 (2018), s.174. 
Hasta güvenliği kültürünü artırmak için çeşitli çalışmalar yapılmıştır. ${ }^{42}$

Hasta güvenliği için etkili iletişim önemini vurgulayan çalışmalar mevcuttur. ${ }^{43}$

Örgüt içerisindeki iç girişimcilik ruhu, doğru belirlenmiş bir vizyon ve amacın, açık iletişimin ve başarı arzusunun bir arada bulunmasıyla harekete geçirilebilir. ${ }^{44} \mathrm{Bu}$ çalışmada iç girişimcilik ile etkili iletişim ilişkisi olduğu ortaya konulmuştur.

Antoncic ve Hisrich, iç girişimciliğin bir örgütte yerleşmesinde ve başarısında belirleyici olarak görülen örgütsel faktörleri; “içsel iletişim”, "biçimsel kontrol mekanizmaları", "çevreyi tarama yoğunluğu” ile ödül ve teşvik sisteminin de yer aldığ “örgütsel ve yönetimsel destek" ve "örgütsel değerler" olarak sıralamıştır. ${ }^{45}$

Çok yönlü bir iletişim sistemin olduğu, formel ilişkilerin yanı sıra gönüllülük esasına dayanan ilişkilerin de var olduğu, çalışanların planlamaya ve karalara katılımının gerçekleştiği işletmeler iç girişimciliğin gelişebilmesi için elverişli bir ortam sunmaktadir. $^{46}$

\section{Araştırma}

\section{Araştırmanın yöntemi}

Kesitsel ve tanımlayıcı bir çalışma tasarımı kullanılmıştır. Araştırmanın evrenini İstanbul ilinde faaliyet gösteren 2 şubesi olan özel hastane çalışanları oluşturmaktadır. A şubesinde 135 yatak, 6 ameliyathane, 3 doğumhane, 51 yataklı 4 yoğun bakım ünitesi ve 250 personel bulunmaktadır. B şubesinde 250 yatak, 7 ameliyathane ve 350 personel bulunmaktadır. Çalışanlara basit rastgele yöntem ile ve çalışmaya katılmayı kabul edilen 498 kişiye anket uygulanmıştır. Araştırma Eylül 2018-Aralık 2018 tarihleri arasında yapılmıştır.

Araştırma anketi: 6 adet sosyo-demografik soru, 5 adet Etkili İletişim Ölçeği madde-

42 İlknur Gül, "Kalite Yönetim Sistemi Çerçevesinde Hasta Güvenliği Kültürünün Çalışma Ortamı Açısından Belirlenmesine Yönelik Bir Araştırma”, Yüksek Lisans Tezi, İstanbul Üniversitesi, 2010, s.97. Xianqiong Feng vd., "The Relationship Between Management Commitment and Patient Safety Culture”, International Nursing Review, 58/2, (2011), s.252. Raeda Fawzi AbuAlRub ve Eyad Hani Abu Alhijaa, “The Impact of Educational Interventions on Enhancing Perceptions of Patient Safety Culture Among Jordanian Senior Nurses", Nursing Forum, 49/2 (2014), s.147. Aysel Balçık Akman, "Hasta Güvenliği Kültürü ve Bir Üniversite Hastanesinde Çalışan Hemşirelerin Hasta Güvenliği Kültürü ile ilgili Algılarını Etkileyen Faktörlerin Değerlendirilmesine Yönelik Bir Araştırma”, Yüksek Lisans Tezi, İstanbul Üniversitesi, 2010, s.135. Fehmi Hasan Dirik, “Çalışma Ortamı ve Güçlendirmenin Hasta Güvenliği Kültürüne Etkisi”, Yüksek Lisans Tezi, Dokuz Eylül Üniversitesi, 2014, s.44. Bektemür, "İç Girișimciliğin Hasta”, s.174.

43 Michael Leonard, Sophie Graham ve Doug Bonacum, “The Human Factor: The Critical Importance of Effective Teamwork and Communication in Providing Safe Care", Qual Saf Health Care, 13/1 (2004), s.87. Paul Gluck, "Patient Safety: Some Progress and Challenges", Obs. Gynecol, 120/5 (2012), 1155. Jennifer Weller, Matt Boyd ve David Cumin, “Teams, Tribes and Patient Safety: Overcoming Barriers To Effective Teamwork in Healthcare", Postgrad Med J, 90/1 (2014), s.150. Nathaniel L. Robinson, "Promoting Patient Safety with Perioperitve Hand-off Communication”, Journal of PeriAnesthesia Nursing, 31/3 (2016): s. 247.

44 Marguerite Elizabeth Hill, "The Development Of An Instrument To Measure Intrapreneurship: Entrepreneurshıp Within The Corporate Setting”, Yüksek Lisans Tezi, Güney Afrika, 2003, s.20.

45 Bostjan Antoncic ve Robert D. Hisrich, "Intrapreneurship: Construct Refinement and Cross-Culturel Validation”, Journal of Business Venturing, 16/5 (2001), s.501.

46 Esra Burcu Bulgurcu Gürel, “İç Girişimcilik: Bir Literatür Taramas1”, Gümüşhane Üniversitesi, Sosyal Bilimler Elektronik Dergisi, 3/6 (2012), s.73. 
si, 42 adet Hasta Güvenliği Kültürü Ölçeği maddesi ve 15 adet İç Girişimcilik ölçeği maddesi olmak üzere toplam 68 maddeden oluşmaktadır.

Araştırmanın ölçeklerinde kullanılmış olan değişkenler, yapılmış olan literatür taramaları esnasında titiz bir şekilde incelenip belirlenen ve farklı insanlar tarafindan değişik hakemli makaleler ve tezlerde kullanılmış olan, orijinali İngilizce ve Türkçe olan ölçeklerdir. Ölçeklerde yer almış olan maddeler, bilimsel yöntemlerle geliştirilen, geçerlilikleri ve güvenilirlikleri yapılmış arattırmalarla test edilen ve kullanılabilirliği tespit edilen maddelerdir.

Araştırmanın ilk değişkeni etkili iletişim ölçeğidir. Bu ölçek Elsamen ve Alshurideh $^{47}$ tarafından kullanılmış ve Urk tarafindan Türkçe’ye çevrilerek kullanılmıştır. Ölçeğin maddeleri 5'li Likert tarzında (1-Kesinlikle Katılmıyorum, 2-Katılmıyorum, 3-Kararsızım, 4-Katılıyorum, 5-Kesinlikle Katılıyorum) hazırlanmıştır. Ölçeğin geçerlilik ve güvenirliği 2015 yılında Urk tarafından yapılarak kullanılmıştır. Cronbach alfa iç tutarlılık katsayısı; etkili iletişim 0,84 olarak bulunmuştur. Türkçe geçerlik ve güvenirlik çalışması yapılan ölçeğin Türk kültürü için yeterli sosyometrik özelliklere sahip bir ölçme aracı olduğu bulunmuştur. ${ }^{48}$

Araştırmanın ikinci değişkeni olan iç girişimcilik seviyesini tespit etmek için öncelikle, yayın taraması yapılmış ve Durmaz’ın 2011 doktora tezinde kullandığı iç girişimcilik ölçeği bulunmuştur. İç girişimciliğin boyutları yenilikçilik, risk alma ve proaktiflik olarak belirlenmiştir. Ölçek, 5'li Likert tarzında (1-Kesinlikle Katılmıyorum, 2-Katılmıyorum, 3-Kararsızım, 4-Katılıyorum, 5-Kesinlikle Katılıyorum) hazırlanmıştır. Araştırmada kullanılacak tüm ölçeğin, geçerlik ve güvenirlik analizleri Durmaz tarafından yapılarak kullanılmıştır. ${ }^{49}$

İç girişimcilik ölçeğinin geçerlik, güvenirlik çalışmasını yapan Durmaz’nn yazdığı tez incelenirse alt boyutlara ait Cronbach alfa iç tutarlılık katsayıları; yenilikçilik 0,851, risk ve proaktiflik 0,902'dir. Türkçe geçerlilik ve güvenirlilik çalışması yapılan ölçek, Türk kültürü için yeterli sosyometrik özelliklere sahip bir ölçme aracı olduğu bulunmuştur. ${ }^{50}$

Hasta güvenliği kültürü anketi, Agency for Healthcare Research and Quality (AHRQ) tarafından 2004 yılında geliştirilmiş olan "Hospital Survey on Patient Safety Culture" anketinin Türkçe'sidir (Sorra ve Nieva, 2004). ${ }^{51}$ Sağlık çalışanlarının hasta güvenliği, tıbbi hata ve olay raporlama konusunda ki görüşlerini değerlendirmek amacı ile AHRQ tarafından geliştirilerek 2004 yılında yayınlanan Hasta Güvenliği Kültürü

47 Amjad A. Elsamen ve Muhammed Alshuride, “The Impact of Internal Marketing on Internal Service Quality: A Case Study in a Jordanian Pharmaceutical Company", International Journal of Business and Management, 7/19 (2012), s.89.

48 Murat Urk, "İçsel Pazarlama Uygulamalarının Çalışan Bağlılığı ile Müşteri ve Şirket Performansına Etkisinin Analizinde Kişilik Özelliklerinin Düzenleyici Rolü” Doktora Tezi, Haliç Üniversitesi, 2015, s.101.

49 Irmak Durmaz, "Psikolojik Güçlendirme Algısının İç Girişimcilik Üzerine Etkisi”, Doktora Tezi, Gazi Üniversitesi, 2013, s.119.

50 Durmaz, "Psikolojik Güçlendirme..." s.120.

51 Joanna Sorra ve Veronica Nieva, Hospital Survey on Patient Safety Culture, Rockville, MD: AHRQ Publ., 2004, s. 10 . 
Hastane Anketi 42 madde ve 12 boyuttan meydana gelmiştir. Emel Filiz tarafından 2009 yılında yapılan "Hastanede Hasta Güvenliği Kültürü Algılamasının ve Sağlık Çalışanları ile Toplumun Hasta Güvenliği Hakkındaki Tutumunun Belirlenmesi” adlı çalışmasında geçerlilik ve güvenilirlik çalışması yapılarak literatüre kazand1rılmıştır. Ankette hasta güvenliği kültürünün boyutlarını ünite/birim düzeyinde ve hastane düzeyinde ölçen sorular ile, sonuç değişkenlerinin yer aldığı sorular bulunmaktadir. ${ }^{52}$

Cevaplanmada A, B ve F bölümlerinde "kesinlikle katılmıyorum", "katılmıyorum", "ne katılıyorum ne katılmıyorum", "katılıyorum", "kesinlikle katılıyorum" ifadeleri, C ve D bölümlerinde "hiçbir zaman", "nadiren”, "bazen”, “çoğu zaman”, "her zaman” ifadeleri kullanıldı.

Araştırma kapsamındaki kısıtlılıklar şu şekilde ifade edilebilir:

Araştırmanın İstanbul bölgesinde faaliyet gösteren 2 şubeli özel hastane çalışanları üzerinde yapılması kapsam yönünden sınırlılık olarak ifade edilebilir.

Araştırma kapsamında hazırlanan anketleri cevaplayan çalışanların gerçekci ve tarafsız olarak anketi cevaplandırdıkları kabul edilmiştir. Fakat anketi cevaplandıran çalışanların sosyal beğenirlik etkisiyle verdikleri cevaplar kullanılan anket metodu bakımından araştırmanın diğer bir sınırlılığı olarak düşünülebilinir. Bu problem farklı değişkenleri birden fazla maddeyle ölçülüp ortalamalarının alınması suretiyle aşılmaya çalışılmıştır.

Etkili iletişim, hasta güvenliği kültürü ve iç girişimcilik arasında olan ilişki, belirli bir tek zaman kesitinde incelenmiştir. Verilerin anlık (cross-sectional) olarak toplanması ve zaman içinde değişimin de belirlenebilmesi için değişik zamanlarda araştırmanın yapılamaması, konuları bu araştırmanın sınırlıkları olarak görülmektedir.

Araştırmanın hipotezleri;

Hipotez 1: Etkili iletişimin hasta güvenliği kültürü üzerinde etkisi bulunmaktadır.

Hipotez 2: Etkili iletişimin iç girişimcilik üzerinde etkisi bulunmaktadır.

Hipotez 3: İç girişimciliğin hasta güvenliği kültürü üzerinde etkisi bulunmaktadır.

Hipotez 4: İç girişimciliğin etkili iletişimin hasta güvenliği kültürü üzerinde aracı değişken olarak etkisi bulunmaktadır.

\section{Bulgular}

\section{Katılımcıların Demografik Özelliklerine İlişkin Bulgular}

Katılımcıların demografik özelliklerine ait bulgular bölümünde, araştırmaya katılmayı kabul edenlerin cinsiyetleri, medeni durumları, yaşları, eğitim durumları, haftalık çalışma saatleri ve mesleklerine ait olan bilgiler incelenmiş, her bir değişkene

52 Emel Filiz, "Hastanede Hasta Güvenliği Kültürü Algılamasının ve Sağlık Çalışanları İle Toplumun Hasta Güvenliği Hakkındaki Tutumunun Belirlenmesi”, Yüksek lisans tezi, Selçuk Üniversitesi, 2009, s.25. 
ilişkin frekans (sıklık) ve yüzde değerlerine yer verilmiştir. Bu değerler Tablo 1'de gösterilmektedir.

Tablo 1. Katılımcıların Sosyo-Demografik Özellikleri

\begin{tabular}{|c|c|c|c|}
\hline \multicolumn{2}{|l|}{ Değişken } & $n$ & $\%$ \\
\hline \multirow{3}{*}{ Cinsiyet } & Kadın & 376 & 75,5 \\
\hline & Erkek & 122 & 24,5 \\
\hline & Toplam & 498 & 100 \\
\hline \multirow{4}{*}{ Medeni Durum } & Evli & 273 & 54,8 \\
\hline & Bekar & 222 & 44,6 \\
\hline & Cevapsız & 3 & 0,6 \\
\hline & Toplam & 498 & 100 \\
\hline \multirow{7}{*}{ Yaş } & $15-20$ & 30 & 6,0 \\
\hline & $21-25$ & 118 & 23,7 \\
\hline & $26-30$ & 114 & 22,9 \\
\hline & $31-35$ & 94 & 18,9 \\
\hline & $36-40$ & 79 & 15,8 \\
\hline & 41ve üstü & 63 & 12,7 \\
\hline & Toplam & 498 & 100 \\
\hline \multirow{5}{*}{ Öğrenim Durumu } & Lise & 127 & 25,5 \\
\hline & Önlisans & 149 & 29,9 \\
\hline & Lisans & 147 & 29,5 \\
\hline & Lisans üstü & 75 & 15,1 \\
\hline & Toplam & 498 & 100 \\
\hline \multirow{4}{*}{$\begin{array}{l}\text { Haftalık Çalışma } \\
\text { Saati }\end{array}$} & 40 saat & 138 & 27,7 \\
\hline & 41-50 saat & 251 & 50,4 \\
\hline & 51 ve üstü saat & 109 & 21,9 \\
\hline & Toplam & 498 & 100 \\
\hline \multirow{6}{*}{ Meslek } & Doktor & 35 & 7,0 \\
\hline & Hemşire & 243 & 48,8 \\
\hline & Sağlık teknikeri/teknisyeni & 72 & 14,5 \\
\hline & Sağllk memuru & 33 & 6,6 \\
\hline & Diğer & 115 & 23,1 \\
\hline & Toplam & 498 & 100 \\
\hline
\end{tabular}

Tablo incelendiğinde; cinsiyetlerine bakıldığında, \%75,5’i kadın, Medeni durumlarına bakıldığında; \%54,8'i evli, Yaşlarına bakıldığında; \%87,3'ünün 40 yaş altında olduğu görülmektedir. Öğrenim durumlarına bakıldığında; \%29,9’u ön lisans, \%29,5’i lisans mezunu olduğu görülmektedir. Haftalık çalışma saatlerine bakıldığında; \%50,4'si 41 50 saat arasında çalıştığını beyan etmiştir. Mesleklerine bakıldığında; araştırmaya katılanların \%48,8'inin hemşire olduğu görülmektedir. 


\section{Geçerlilik ve Güvenirlik}

Araştırması yapılan ve 498 kişiye uygulanan ölçeğin toplam 62 maddesine Cronbach Alpha güvenirlik testi uygulanmıştır. Sonuç olarak etkili iletişim ölçeğinin değeri 0,865; iç girişimcilik ölçeğinin değeri 0,861 ; hasta güvenliği kültürü ölçeğinin değeri 0,894 ve genel ölçeğin değeri ise 0,908 bulunmuştur. Bu sonuçlara göre araştırma ölçeğinin güvenilir olduğu söylenebilir.

\section{Tanımlayıcı İstatistikler}

Tablo 2. Tanımlayıcı İstatistikler

\begin{tabular}{|c|l|c|c|c|}
\hline Sıra No. & Ölçek & Aralık & $x$ & s.s \\
\hline 1. & Etkili İletişim & $1-5$ & 3,47 &, 79 \\
\hline 2. & İç Girişimcilik & $1-5$ & 3,77 &, 53 \\
\hline 3. & Hasta Güvenliği Kültürü & $1-5$ & 3,36 &, 40 \\
\hline
\end{tabular}

x: ortalama s.s.: standart sapma

Tanımlayıcı istatistikler tablo 2 de olduğu gibidir. Etkili iletişimin ortalama sonucu 3,47 ve standart sapması ,79 olarak bulunmuştur. İç girişimciliğin ortalama sonucu 3,77 ve standart sapması ,53 olarak bulunmuştur. Hasta güvenliği kültürü ortalama sonucu 3,36 ve standart sapması ,40 olarak bulunmuştur.

\section{Değişkenler Arasındaki İlişkiler}

Tablo 3. Tüm Değişkenler Arasındaki İlişkiler

\begin{tabular}{|c|c|c|c|c|}
\hline \multicolumn{2}{|c|}{ Değişkenler $(n=498)$} & \multirow{2}{*}{$\frac{\dot{I}_{\text {ç girişimcilik }}}{1}$} & \multirow[t]{2}{*}{ Etkili iletişim } & \multirow[t]{2}{*}{ Hasta güvenliği kültürü } \\
\hline İç girişimcilik & $\mathrm{r}$ & & & \\
\hline \multirow{2}{*}{ Etkili iletişim } & $\mathrm{r}$ &, $402^{* *}$ & \multirow{2}{*}{1} & \\
\hline & $\mathrm{p}$ &, 000 & & \\
\hline \multirow{2}{*}{$\begin{array}{l}\text { Hasta Güvenliği } \\
\text { Kültürü }\end{array}$} & $\mathrm{r}$ &, $196^{* *}$ &, $452^{* *}$ & \multirow{2}{*}{1} \\
\hline & $\mathrm{p}$ & 001 &, 000 & \\
\hline
\end{tabular}

${ }^{* *} \mathrm{r} 0,01$ anlamlılık düzeyinde,

Tablo incelendiğinde hasta güvenliği kültürü değişkeni ile etkili iletişim arasında $(\mathrm{r}=0,452, \mathrm{p}<0,001)$ istatistiksel olarak anlamlı pozitif, doğrusal ve orta bir ilişki elde edilmiştir. Hasta güvenliği kültürü değişkeni ile iç girişimcilik arasında $(r=0,196$, $\mathrm{p}<0,001$ ) istatistiksel olarak anlamlı pozitif, doğrusal ve zayıf bir ilişki elde edilmiştir. İç girişimcilik değişkeni ile etkili iletişim arasında $(r=0,402, p<0,001)$ istatistiksel olarak anlamlı pozitif, doğrusal ve orta bir ilişki elde edilmiştir.

\section{Değişkenler Arasındaki Nedensellik Analizleri}

Değişkenler arasındaki etki analizleri ve aracı etki analizi yapılmış ve sonuçlar analiz edilmiştir. Analizler için basit regresyon analizi ve hiyerarşik regresyon analizleri yapilmıştır. 
Araştırmanın birinci hipotezi kapsamında etkili iletişimin hasta güvenliği kültürü üzerindeki etkisi incelenmiştir. Buna yönelik yapılan basit regresyon analizi sonuçları değerlendirilmiş ve yorumlar yapılmıştır.

Tablo 4. Etkili İletişimin Hasta Güvenliği Kültürü Bağımlı Değişkeni İçin Etki Analizi Tablosu

\begin{tabular}{|l|l|l|l|l|l|}
\hline Değişken & $B$ & Standart hata & Beta & $t$ & $p$ \\
\hline Sabit & 2,599 &, 085 & & 35,362 &, 000 \\
Etkili İletişim &, 217 &, 028 &, 452 & 11,276 &, 000 \\
\hline $\mathrm{N}=498$, & & & \\
$\mathrm{R}=0,452, \mathrm{R}^{2}=0,204$, Düzel. $\mathrm{R}^{2}=0,202$, & & \\
$\mathrm{F}=127,146, \mathrm{p}<0,001$ & & & \\
\hline
\end{tabular}

Basit doğrusal regresyon analizi sonucunda etkili iletişimin hasta güvenliği kültürü ile orta düzeyde ve anlamlı bir ilişkiye sahip olduğu bulunmuştur $\left(R=, 452, \mathrm{R}^{2}=, 204\right.$, $\mathrm{p}<0,001)$. Buna sonuca göre etkili iletişimin toplam varyansın \%20'sini açıklamaktadır. Standardize edilmiş beta katsayısı ve t değerleri incelendiğinde bağımsız değişken olan etkili iletişimin bağımlı değişken olan hasta güvenliği kültürünü anlamlı bir şekilde etkilediği söylenebilir $(\mathrm{t}=11,276, \mathrm{p}<, 001)$. Kurulan modelinde anlamlı olduğu görülmektedir $(\mathrm{F}=127,146, \mathrm{p}<0,001)$.

Araştırmanın ikinci hipotezi kapsamında etkili iletişimin iç girişimcilik üzerindeki etkisi incelenmiştir. Buna yönelik yapılan basit regresyon analizi sonuçları değerlendirilmiş ve yorumlar yapılmıştır

Tablo 5. Etkili İletişim İç Girişimcilik Bağımlı Değişkeni İçin Etki Analizi Tablosu

\begin{tabular}{|l|l|l|l|l|l|}
\hline Değiş̧en & $B$ & Standart hata & Beta & $t$ & $p$ \\
\hline Sabit & 2,834 &, 099 & & 28,699 &, 000 \\
Etkili iletişim &, 271 &, 028 &, 402 & 9,791 &, 000 \\
\hline $\mathrm{N}=498$, \\
$\mathrm{R}=0,402, \mathrm{R}^{2}=0,162$ Düzel. $\mathrm{R}^{2}=0,160$, \\
$\mathrm{F}=95,863, \mathrm{p}<0,001$
\end{tabular}

Basit doğrusal regresyon analizi sonucunda etkili iletişimin iç girişimcilik ile orta düzeyde ve anlamlı bir ilişkiye sahip olduğu bulunmuştur $\left(R=, 271, R^{2}=, 162, p<0,001\right)$. Buna göre sonucunda etkili iletişim toplam varyansın \%16 sını açıklamaktadır. Standardize edilmiş beta katsayısı ve t değerleri incelendiğinde bağımsız değişken olan etkili iletişimin bağımlı değişken olan iç girişimciliği anlamlı bir şekilde etkilediği söylenebilir ( $\mathrm{t}=28,699, \mathrm{p}<, 001)$. Kurulan modelinde anlamlı olduğu görülmektedir $(\mathrm{F}=95,863, \mathrm{p}<0,001)$.

Araştırmanın üçüncü ve dördüncü hipotezi kapsamında iç girişimciliğin hasta güvenliği üzerindeki etkisi ve aracı değişken özelliği incelenmiştir. Buna yönelik yapılan hiyerarşik regresyon analizi sonuçları değerlendirilmiş ve yorumlar yapılmıştır. 
Tablo 6. İç Girişimciliğin Hasta Güvenliği Kültürü Bağımlı Değişkeni İçin Etki Analizi Tablosu

\begin{tabular}{|l|l|l|l|l|l|}
\hline Değişken & $B$ & Standart hata & Beta & $t$ & $p$ \\
\hline Sabit & 2,808 &, 127 & & 22,159 &, 000 \\
İç girişimcilik &, 148 &, 033 &, 196 & 4,447 &, 000 \\
\hline $\mathrm{N}=498$, \\
$\mathrm{R}=0,196, \mathrm{R}^{2}=0,038$, Düzel. $\mathrm{R}^{2}=0,036$, \\
$\mathrm{F}=19,772, \mathrm{p}<0,001$
\end{tabular}

Basit doğrusal regresyon analizi sonucunda iç girişimciliğin hasta güvenliği kültürü ile zayıf düzeyde ve anlamlı bir ilişkiye sahip olduğu bulunmuştur $(\mathrm{R}=, 196$, $\left.\mathrm{R}^{2}=, 038, \mathrm{p}<0,001\right)$. Buna göre sonucunda etkili iletişimin toplam varyansin \%4'ünü açıllamaktadır. Standardize edilmiş beta katsayısı ve $t$ değerleri incelendiğinde bağımsız değişken olan iç girişimciliğin bağımlı değişken olan hasta güvenliği kültürünü anlamlı bir şekilde etkilediği söylenebilir $(\mathrm{t}=4,447, \mathrm{p}<, 001)$. Kurulan modelinde anlamlı olduğu görülmektedir $(\mathrm{F}=19,772, \mathrm{p}<0,001)$.

Etkili iletişimin hasta güvenliği kültürüne etkisini ve bu etkide iç girişimciliğin aracı rolünü belirlemeye yönelik olan bu araştırmada, hipotezleri test etmek maksadıyla hiyerarşik regresyon analizleri yapılmıştır. Hipotezleri sınamak için yapılan hiyerarşik regresyon analizinde etkili iletişim bağımsız değişken, hasta güvenliği kültürü bağımlı değişken ve iç girişimcilikte aracı değişken olarak modele dâhil edilmiştir (Tablo 7).

Tablo 7. Etkili İletişim ve İç Girişimciliğin Hasta Güvenliği Kültürü Bağımlı Değişkeni İcin Etki Analizi Tablosu

\begin{tabular}{|l|l|l|l|l|l|l|l|}
\hline Değişken & $B$ & Standart hata & Beta & $t$ & $p$ & tolerance & VIF \\
\hline Sabit & 2,599 &, 085 & & 35,293 &, 000 & & \\
Etkili iletişim &, 217 &, 028 &, 452 & 11,950 &, 000 & & \\
\hline Sabit & 2,532 &, 119 & & 21,360 &, 000 & & \\
Etkili iletişim &, 226 &, 022 &, 445 & 10,160 &, 000 &, 838 & 1,193 \\
Iç girişimcilik &, 013 & 0,33 &, 017 &, 382 &, 703 &, 838 & 1,193 \\
\hline $\begin{array}{l}\text { Model 1 } \\
\text { N=498, } \\
\mathrm{R}=0,452, \mathrm{R} 2=0,204, \text { Düzel. } \mathrm{R} 2=0,202, \\
\mathrm{~F}=127,146, \mathrm{p}<0,001\end{array}$ & $\begin{array}{l}\text { Model 2 } \\
\mathrm{N}=498, \\
\mathrm{R}=0,452, \mathrm{R} 2=0,204, \text { Düzel. } \mathrm{R} 2=0,201,\end{array}$ \\
$\mathrm{~F}=63,536, \mathrm{p}<0,001$ \\
Durbin-Watson=1,506
\end{tabular}

Tablo 7 incelendiğinde etkili iletişim ve iç girişimcilik bağımsız değişkenlerindeki değişimin, hasta güvenliği kültürü bağıml değişkendeki değişimin \%20,4'ünü açılayabildiği görülmektedir. ANOVA testi, kurulan modelin genel olarak anlamlı olduğunu göstermektedir $(\mathrm{F}=63,536 ; \mathrm{p}<0,001)$. Beta değerlerine bakıldığında etkili iletişimin bağımsız değişkeninin modelin açıklayıcılığına daha fazla katkı sağladığı 
görülmektedir (Beta= 445). Baron ve Kenny’nin (1986) üçüncü koşulunun test edilmesi amacıyla yapılan regresyon analizi sonuçlarına göre etkili iletişim bağımsız değişkeninin hasta güvenliği kültürü üzerindeki etkisi $(B=, 217$; Beta $=, 452)$, arac1 değişken olarak önerilen iç girişimciliğin analize dahil edildiğinde $(B=, 226$; Beta= ,445) B değeri artarken beta değeri azalmaktadır. Bu durumda iç girişimciliğin, etkili iletişim ile hasta güvenliği kültürü arasında aracı değişken rolü üstlenmediği söylenebilir. Bağımsız değişken etkisinin son analizde tamamen ortadan kalkmaması ve azalmaması bu ilişkide başka aracı değişkenlerin varlığına işaret etmektedir. ${ }^{53}$ $\mathrm{Bu}$ da etkili iletişimin hasta güvenliği kültürü ile ilişkisinde iç girişimciliğin aracı değişken olmadığını göstermektedir.

Araştırmada elde edilen bulgulara göre; araştırmanın birinci, ikinci ve üçüncü hipotezi desteklenmiştir. Araştırmanın dördüncü hipotezi desteklenmemiştir.

\section{Tartışma}

Araştırmanın birinci hipotezi etkili iletişimin hasta güvenliği kültürünü etkilediği yönünde idi. Yapılan analizler sonucunda; iletişimde 1 birimlik artışın hasta güvenliği kültüründe 0,217 birimlik bir artışa neden olmaktadır. Literatürde aynı paralellikte birçok çalışma bulunmaktadır. Etkili iletişimin hasta güvenliği ve güvenlik için raporlamanın iyileştirilmesin katkı sağladığı yönünde çalışmalar bulunmaktadır. ${ }^{54}$ Weller ve ark (2014) yılında yaptıkları çalışmada etkili iletişim hasta sonuçlarının olumlu çıkması için önemli olduğu vurgulamıştır. ${ }^{55}$ Josepha ve ark. (2018) yılında yaptıkları çalışmada danışmanlar tarafından geliştirilen iletişim teknikleri ve stratejileri hasta çıktılarını olumlu etkilemekte olduğu sonucuna varmışlardır. ${ }^{56}$ Lyndon ve ark. (2011) yılında, Park ve ark. (2018) yılında ve Huang ve ark. (2018) yılında yapmış oldukları çalışmalarda hemşireler ve hekimler arasındaki iletişimin hasta güvenliği için kritik öneme sahip olduğunu vurgulamışlardır. ${ }^{57}$ Muraldihar ve ark. (2012) yaptıkları çalışmada eksik ve yetersiz iletişimin hasta güvenliği için büyük problemlere neden olduğunu vurgulamıştırlar. ${ }^{58}$

Araştırmanın ikinci hipotezi etkili iletişimin iç girişimciliği etkilediği yönünde idi. Yapılan analizler sonucunda; iletişimde 1 birimlik artışın hasta güvenliği kültüründe 0,271 birimlik bir artışa neden olmaktadır. Göçmen (2007) yaptığı çalışmada iç

53 Reuben M. Baron ve David A. Kenny, “The Moderator-Mediator Variable Distinction İn Social Psychological Research: Conceptual, Strategic, and Statistical Considerations”. Journal of Personality and Social Psychology, 51/6 (1986), s.1180.

54 Malin Mattson, Johnny Hellgren ve Sara Goransson, "Leader Communication Approaches and Patient Safety: An Integrated Model”, Journol of Safety Research, 53/2, (2015), s.55.

55 Weller, Boyd ve Cumin, “Teams, Tribes" s.151.

56 Galen Josepha vd., "Effective Communication in The Era of Precision Medicine: A Pilot İntervention With Low Health Literacy Patients to İmprove Genetic Counseling Communication", European Journal of Medical Genetics, 62/5 (2018), s.365.

57 Lyndon, Zlantik ve Wachter, "Effective Physician-Nurse" s.94. Kwang-Ok Park, Sung-Hee Park ve Mi Yu, "Physicians' Experinxce of Communication with Nurses related to Patient Safety: A Phenomenological Study Using the Colaizzi Method", Asian Nursing Research, 12/3 (2018), s.172. Huang, Wu, ve Lee, "The Perceptions of Patient", s.44.

58 Sumathi Muralidhara, Akhil Tanejab ve Visvanathan Ramesha, "Patient Safety Culture-Perception of Health Care Workers, in A Tertiary Care Hospital”, International Journal of Risk \& Safety in Medicine, 24/4 (2012), s.197. 
girişimciliği artırmaya yönelik çalışmalarda, çalışanların terfi ile iletişim kriterinin önemli olduğu sunucuna ulaşmıştır. ${ }^{59}$ İletişimin ve örgütsel değerlerin iç girişimcilik üzerine etkisinin olduğu bulunmuştur. ${ }^{60}$

Araştırmanın üçüncü hipotezi iç girişimciliğin hasta güvenliği kültürünü etkilediği yönünde idi. Yapılan analizler sonucunda; iç girişimcilikteki 1 birimlik artışın hasta güvenliği kültüründe 0,148 birimlik bir artışa neden olmaktadır. Bektemür (2018) yaptığı çalışmada iç girişimciliğinin hasta güvenliği kültürünü etkilediği sonucuna ulaşmıştır. ${ }^{61}$

Araştırmanın dördüncü hipotezi etkili iletişimin hasta güvenliği kültürü üzerine etkisinde iç girişimciliğin aracı rolü olduğu yönünde idi. Yapılan analizler sonucunda; iç girişimciliğin etkili iletişim hasta güvenliği kültürü üzerinde etkisini azaltmadığ 1 görülmüştür. Bu da iç girişimciliğin aracı değişken olmadığını desteklemektedir. İç girişimcilikte risk almak önemli bir boyuttur. Ancak hastaları riske atmak tehlikeli olduğundan rutin uygulamaların dışına çıkılmaması gerekir. Bu sebeple iç girişimciliğin hasta güvenliği kültürü üzerinde etkili iletişimin etkisini azaltamadığ ve ortadan kaldıramadığı düşünülmektedir.

\section{Sonuç}

Sağlık sisteminde etkili iletişim hataları önlemek ve iş memnuniyetini artırmak için çok önemlidir. Doktorlar ve hemşireler iletişimlerinin kalitesini algılamayı kabul etmemeye devam ediyorlar. Potansiyel çözümler literatürde tanımlanmıştır. Hastane yöneticilerinin, doktor ve hemşire liderleri ve tıp ve hemşirelik eğitim kurumları gelişmiş iletişimi destekleyen ekip dinamiklerinde kalıcı değişiklikleri sahnelemek için tam zamanıdır. ${ }^{62}$

$\mathrm{Bu}$ nedenle, sağlık profesyonelleri arasındaki etkili iletişim, iş birliği için gereken temel olabilir. $\mathrm{Bu}$ nedenle, hastane yöneticileri ve birim yöneticileri, hemşireler ve doktorlar arasındaki etkili iletişimi geliştirmek için faaliyetlerde bulunabilirler. $\mathrm{Bu}$ iletişim odaklı faaliyetler, bu çalışmaya göre çalışan iş birliğini de artırabilecek etkin iletişimi geliştirebilir. Bu nedenle, sağlık hizmeti yöneticileri iletişim için yapılandırılmış araçların kullanımını savunabilir. İletişimin önemi birçok çalışmada ortaya konulmuştur. İletişimin etkilediği birçok etken bulunmaktadır. İletişimin hasta güvenliği kültürünü artırdığı ortaya konulmuştur. İç girişimciliğin, bu etkiyi ortadan kaldırmadığı ve azaltmadığı görülmemiştir. Bu da iç girişimciliğin aracı değişken olmadığı kabul edilmiştir.

Hasta güvenliği kültürünü artırmak için kurum içi iletişimin etkinliği ortaya koyabilecek iletişim sistemi kurulması yöneticilere önerilebilir. Araştırmacılara ise;

59 Selin Göçmen, “İşletmelerde Girişimcilik Özelliğini Destekleyen Faktörler: İç Girişimcilik”, Yüksek Lisans Tezi, Celal Bayar Üniversitesi, 2007, s.157.

60 Mustafa Büte, "Örgütsel Faktörlerin İç Girişimcilik Üzerine Etkileri”, EKEV Akademi Dergisi 12/37 (2008), s.57.

61 Bektemür, "İç Girişimciliğin Hasta”, s.175.

62 Childress, “Team Communication”, s.24 
(I) bu çalışmanın kamu ve üniversite hastanelerinde yapılması, (II) hasta güvenliği kültürünü artırabilmek için yeni bağımsız değişkenler ile çalışma yapılması, önerilebilir.

\section{Kaynakça}

AbuAlRub, Raeda Fawzi ve Eyad Hani Abu Alhijaa. “The Impact of Educational Interventions on Enhancing Perceptions of Patient Safety Culture Among, Jordanian Senior Nurses”. Nursing Forum, 49/2 (2014): 139-150.

Ağca, Veysel ve Mustafa Kurt. "İç Girişimcilik ve Temel Belirleyicileri: Kavramsal Bir Çerçeve”. Erciyes Üniversitesi İktisadi ve İdari Bilimler Fakültesi Dergisi. 0/29 (2007): 83-112.

Antoncic, Bostjan ve Robert D. Hisrich. "Clarifying The Intrapreneurship Concept". Journal of Small Business and Enterprise. 10/1 (2003): 7-24.

Antoncic, Bostjan ve Robert D. Hisrich. "Intrapreneurship: Construct Refinement and Cross-Culturel Validation". Journal of Business Venturing. 16/5 (2001): 495527.

Apak, Sudi, Kamer H. Taşçıyan ve Muzaffer Aksoy. Girişimcilik ve Sermaye Tedarik Yöntemleri. İstanbul: Papatya Yayıncılık, 2010.

Balasundaram, Nimalathasan ve Mohammad Shabab Uddin. "Determinants of Key Favorable Environment for Intrapreneurship Development: An Empirical Study of Some Selected Companies in Chittagong, Bangladesh". BULETINUL Universitesi Petrol - Gaze din Ploieşti, LXI/2 (2009): 29-35.

Balçık Akman, Aysel. "Hasta Güvenliği Kültürü ve Bir Üniversite Hastanesinde Çalışan Hemşirelerin Hasta Güvenliği Kültürü ile ilgili Algılarını Etkileyen Faktörlerin Değerlendirilmesine Yönelik Bir Araştırma”. Yüksek Lisans Tezi, İstanbul Üniversitesi, 2010.

Baron, Reuben M. ve David. A. Kenny. “The Moderator Mediator Variable Distinction in Social Psychological Research: Conceptual, Strategic and Statistical Considerations". Journal of Personality and Social Psychology. 51/6 (1986): 11731182.

Bektemür, Güven. "İç Girişimciliğin Hasta Güvenliği Kültürü Üzerine Etkisi: Bir Özel Hastane Uygulaması”. Să̆ Aka Derg. 5/3 (2018): 161-177.

Beyer, Martin, Julia Rohe, Peter J. Nicklin, ve Keith Haynes. Communication and Patient Safety. Massachusetts: Blackwell Publishing Ltd., 2007.

Bokhari, Zülfikar Ali. "Supportıng Entrepreneurshıp and Intrapreneurshıp at Unıversities for Small Business Development from Marketıng Perspective Is The Key to Support Community, Faculty and Students". Contracts With Large Multinational Corporations: A Hurdle, MMA Fall Educators' Conference. 2006.

Bulgurcu Gürel, Esra Burcu. "İç Girişimcilik: Bir Literatür Taraması”. Gümüşhane Üniversitesi, Sosyal Bilimler Elektronik Dergisi. 3/6 (2012): 56-75.

Büte, Mustafa. “Örgütsel Faktörlerin İç Girişimcilik Üzerine Etkileri”. EKEV Akademi Dergisi. 12/37 (2008): 41-67. 
Childress, Susan B. “Team Communication: It's About Patient Safety”. Journal of Oncology Practice. 11/1 (2015): 23-25.

Condrill, Jo ve Bennie Bough. 101 İletişim Yolu. Çev., Aslı Şahin. İstanbul: Beyaz Yayınlar1, 2000.

Dirik, Fehmi Hasan. “Çalışma Ortamı ve Güçlendirmenin Hasta Güvenliği Kültürüne Etkisi”. Yüksek Lisans Tezi, Dokuz Eylül Üniversitesi, 2014.

Domnariu, Carmen Daniela. "Patient Safety Culture at Organizational Level”. Public Health and Management, Acta Medica Transilvanica. 2/3 (2012): 145-147.

Dökmen, Üstün. İletişim Çatışmaları ve Empati. İstanbul: Sistem Yayıncılık, 2003.

Durmaz, Irmak. "Psikolojik Güçlendirme Algısının İç Girişimcilik Üzerine Etkisi”. Doktora Tezi, Gazi Üniversitesi, 2013.

Elsamen, Amjad A. ve Muhammed Alshurideh. “The Impact of Internal Marketing on Internal Service Quality: A Case Study in a Jordanian Pharmaceutical Company". International Journal of Business and Management. 7/19 (2012): 8495.

Faulkner, Ann., Jackie Argent ve Avril Jones. "Effective Communication in Health Care: Exploring The Skills of The Teachers". Patient Education and Counseling. 45/3 (2001): 227-232.

Feng, Xianqiong, Lea Acord, Ya-Jun Cheng, Junchao Zeng ve Juan P. Song. "The Relation Ship Between Management Commitment and Patient Safety Culture". International Nursing Review. 58/2 (2011): 249-254.

Filiz, Emel. "Hastanede hasta güvenliği kültürü algılamasının ve sağlık çalışanları ile toplumun hasta güvenliği hakkındaki tutumunun belirlenmesi”. Yüksek lisans tezi, Selçuk Üniversitesi, 2009.

Gemlik, Nilay. Hastane Yönetiminde 4 Boyut. Ankara: Nobel Akademik Yayıncılık, 2018.

Gluck Paul A. "Patient Safety: Some Progress and Challenges". Obs. Gynecol. 120/5 (2012): 1149-1159.

Göçmen, Selin. "İşletmelerde Girişimcilik Özelliğini Destekleyen Faktörler: İç Girişimcilik” Yüksek Lisans Tezi, Celal Bayar Üniversitesi, 2007.

Gronroos, Christian. Service Management and Marketing. Massachusetts: Lexington Boks, 1990.

Gül, İlknur. "Kalite Yönetim Sistemi Çerçevesinde Hasta Güvenliği Kültürünün Çalışma Ortamı Açısından Belirlenmesine Yönelik Bir Araştırma”. Yüksek Lisans Tezi, İstanbul Üniversitesi, 2010.

Hill, Marguerite Elizabeth. “The Development Of An Instrument To Measure Intrapreneurship: Entrepreneurshıp Within The Corporate Setting”. Yüksek Lisans Tezi, Güney Afrika, 2003.

Hodgetts, Richard M. Yönetim, Teori, Süreçve Uygulama. Çev., Canan Çetin ve Esin Can Mutlu. İstanbul: Beta basım yayım Dağıtım A.Ş., 1999. 
Hua, Ying, Franklin Becker, Teri Wurmser, Jane Bliss-Holtz ve Christine Hedges. "Effects of Nursing Unit Spatial Layout on Nursing Team Communication Patterns, Quality of Care, and Patient Safety”. HERD. 6/1 (2012): 8-38.

Huang, Chih-Hsuan, Hsin-Hung Wu ve Yi-Ching Lee. "The Perceptions of Patient Safety Culture: A Difference Between Physicians and Nurses in Taiwan”. Applied Nursing Research. 40/3 (2018): 39-44.

Institute of Medicine. Keeping Patient Safe: Transforming The Environment of Nurses. Washington DC: National Academy Press, 2004.

İbrahimoğlu, Nurettin ve Özlem Yaşar Uğurlu. “KOBİ’lerde İç Girişimcilik ve Örgüt Kültürü İlişkisi: Sektörel Bir Araştırma”. H.Ü. İktisadi ve İdari Bilimler Fakültesi Dergisi. 31/1 (2013): 103-126.

Josepha, Galen, Robin Lee, Rena J. Pasick, Claudai Guerra, Dean Schillinger, Sara Rubin. "Effective Communication in The Era of Precision Medicine: A Pilot Intervention With Low Health Literacy Patients to İmprove Genetic Counseling Communication”. European Journal of Medical Genetics. 62/5 (2018): 357-367.

Keyton, Joann ve Pamela. Shockley Zalabak. Case Studies for Organizational Communication: Understanding Communication. Los Angeles: Processes Roxbury Publishing Company, 2006.

Kızıldağ, Şaban. İletişimde Mazeret Yok. İstanbul: Hayat Yayınları, 2014.

Leonard Michael, Sophie Graham ve Doug Bonacum. “The Human Factor: The Critical İmportance of Effective Teamwork and Communication in Providing Safe Care". Qual Saf Health Care. 13/1 (2004): 85-90.

Lings, Ian N. ve Gordon E. Greenley. "Measuring Internal Market Orientation”. Journal of Service Research. 7/1 (2005): 290-305.

Lyndon, Audrey, Marya G. Zlantik ve Robert M. Wachter. "Effective Physician-Nurse Communication: A Patient Safety Essential For Labor and Delivery". American Journal of Obstetrics-Gynecology. 205/2 (2011): 91-95.

Matos, Tiago R. "The Challenge of Effective Communication Among Scientists". Journol of Investigative Dermatology. 137/11 (2017): 183-184.

Mattson,Malin, Johnny Hellgren ve Sara Goransson. "Leader Communication Approaches and Patient Safety: An Integrated Model". Journol of Safety Research. 53/2 (2015): 53-62.

Medrano-Mariscala, Joel. "Reflections on The Concept of Communication: Second International Goal of Patient Safety”. Rev Med Inst Mex Seguro Soc. 53/4 (2015): 518-522.

Mortell, Manfred. "Is There a Theory - Practice - Ethics Gap? A Patient Safety Case Study". International Journal of Africa Nursing Sciences. 10/1 (2019): 38-42.

Muralidhara, Sumathi, Akhil Tanejab, ve Visvanathan Ramesha. "Patient Safety Culture-Perception of Health Care Workers, in A Tertiary Care Hospital". International Journal of Risk \& Safety in Medicine. 24/4 (2012): 191-199. 
Norouzi, Nima, Maryam Shabak, Mohamed Rashid Bin Embic ve Tareef Hayat Khand. "The Architect, The Client and Effective Communication In Architectural Design Practice”. Procedia-Social and Behavioral Sciences. 172/1 (2015): 635-642.

Olusegun, Ayodele Elijah, A. V. O. "Communications İn The Building İndustry of Nigeria- İmplications For Clients”. 2004: 51-56.

Park, Kwang-Ok, Sung-Hee Parkve Mi Yu. “Physicians' Experinxce of Communication with Nurses related to Patient Safety: A Phenomenological Study Using The Colaizzi Method". Asian Nursing Research. 12/3 (2018): 166-174.

Paterson, Margo, Jennifer Medves, Nancy Dalgarno, Anne O'Riordan, Robyn Grigg. "The Timely Open Communication for Patient Safety Project". Journal of Research in Interprofessional Practice and Education. 3/1 (2013): 22-42.

Robinson, Nathaniel L. "Promoting Patient Safety with Perioperitve Hand-off Communication”. Journal of PeriAnesthesia Nursing. 31/3 (2016): 245-253.

Sorra, Joanna S. ve Veronica F. Nieva. Hospital Survey on Patient Safety Culture. Rockville, MD: AHRQ Publ., 2004.

Şahbaz, Ahmet ve Ümran Şahbaz. “İnovasyon ve Girişimcilik”. Uluslararası Girişimcilik ve Kariyer Sempozyumu. 1-3 Kasım, 2013.

Tak, Bilçin. "Sağlık Hizmetlerinde Kalitenin Ana Unsuru Olarak Hasta Güvenliği Sistemlerinin Oluşturulması: Hastaneler İçin Bir Yol Haritası Önerisi”. Sağlıkta Performans ve Kalite Dergisi. 1/1 (2010): 72-114.

T.C. Sağlık Bakanlığı. SKS ışı̆̆ında Sağlıkta Kalite Kitabı, Cilt 2. Ankara: Sağlık Hizmetleri Genel Müdürlüğ̈̈, 2012.

The Joint Commission. "Advancing Effective Communication, Cultural Competence, and Patient- and Family-Centered Care: A Roadmap For Hospitals”. Erişim 18 Mart 2019 http://www.jointcommission.org/assets/1/6/ ARoadmapforHospitalsfinalversion727.pdf.

The Joint Commission. "National Patient Safety Goals: Long Term Care Program". Erişim 18 Mart, 2019. http://www.jointcommission.org/assets/1/6/NPSG_ Chapter_Jan2012_LTC.pdf.

Tjia, Jennifer, Kathleen M., Mazor, Terry Field, Vanessa Meterko, Ann Spenard ve Jerry H. Gurwitz. "Nurse-Physician Communication In The Long-Term Care Setting: Perceived Barriers and Impact on Patient Safety". Journal of Patient Safety, 5/3 (2009): 145-152.

Urk, Murat. "İçsel Pazarlama Uygulamalarının Çalışan Bağlılığı ile Müşteri ve Şirket Performansına Etkisinin Analizinde Kişilik Özelliklerinin Düzenleyici Rolü”. Doktora Tezi, Haliç Üniversitesi, 2015.

Wachter, Robert M. Understanding Patient Safety. Columbus, Ohio: The McGrawHill Companies, 2008.

Weinberg, Joanna K. "Medical Error and Patient Safety: Understanding Cultures in Conflict". Law \& Policy. 24/2 (2002): 93-113. 
Weller, Jennifer, Matt Boyd ve David Cumin. “Teams, Tribes and Patient Safety: Overcoming Barriers To Effective Teamwork in Healthcare". Postgrad Med J. 90/1 (2014): 149-154.

WHO. Patient Safety, Learning From Error. Fransa: WHO Library Cataloguing-inPublication Data. 2010.

Wu, Wann-Yih, Chia-Chun Tsai ve Chen-Su Fu. “The Relationships among Internal Marketing, Job Satisfaction, Relationship Marketing, Customer Orientation, and Organizational Performance: An Empirical Study of TFT-LCD Companies in Taiwan". Human Factors and Ergonomics in Manufacturing \& Service Industries. 23/5 (2013): 436-449.

Yalçın, Şükran ve Adile Acar. "Avrupa Birliği Ülkelerinde Hasta Güvenliği ve Güvenli Hastane İlişkisi”. II. Uluslararası Sağlıkta Performans ve Kalite Kongresi Kitabı, 1/1 (2010): 12-26. 


\title{
The Effect of the Effective Communication on Patient Safety Culture and the Intermediary Role of the Internal Intrapreneurship: A Private Hospital Practice
}

\author{
Alí ArslanoĞLU
}

Abstract: The importance of the patient safety is an increasing issue. It is necessary to increase the patient safety culture for patient safety. The aim of this study is trying to determine the impact of effective communication and the metioting role of internal intrapreneurship to increase patient safety culture. In this study effective communication, internal intrapreneurship and patient safety culture scale was used which had been validated before. A private hospital staff operating in the province of Istanbul constitutes the population of the research. 498 people participated in the study. The study was conducted between september 2018 and December 2018. 75,5\% of the participants were women, $54,8 \%$ were married, $87,3 \%$ were under the age of 40,29,9\% were foundation year; 29,5 were bachelor's degree, 50,4\% were working between 41 and 50 hours per week and 48,8\% were nurses. The correlation of research variables was found as 0,196, 0,402 and 0,452. The hypotheses that effective communication and internal intrapreneurship affect the patient safety culture has been supported. It suopported the hypotheses that effective communication influenced internal intrapreneurship. The hypothesis that internal intrapreneurship has an intermediary effect on the impact of effect communication on patient safety culture has been supported.

Keywords: Effective communication, Internal intrapreneurship, Patient safety culture. 